\title{
Launch of the ABCD Insulin Pump Network UK
}

\author{
EMMA G WILMOT, ${ }^{2}$ PETER HAMMOND, ${ }^{2}$ ROB GREGORY 3
}

\section{Introduction}

The previous NHS diabetes insulin pump network, although short-lived, was one of the most successful networks with over 500 members and an active online forum. Sadly, the network functions ceased with the demise of NHS Diabetes in April 2013. Nonetheless, the number of people living with diabetes who use insulin pumps to manage their diabetes has continued to grow. The authors felt there was an unmet need for collaboration and support for UK insulin pump teams. With thanks to unrelenting support from $A B C D$, the authors and the IPN-UK Committee have successfully managed to reignite a UK-wide insulin pump network.

\section{Benefits of insulin pump therapy}

Insulin pump therapy provides a number of advantages over conventional multiple daily injections (MDI) for the person living with diabetes. The variation in insulin delivery is substantially less, $<3 \%$ for insulin pump therapy compared with up to $55 \%$ for subcutaneous insulin injections, which translates into more consistent and predictable blood glucose results which can increase confidence in self-management and improve quality of life. ${ }^{1}$ Proven benefits from insulin pump therapy use include an improvement in glycaemic control in addition to a reduction in the frequency and severity of hypoglycaemia. ${ }^{2}$ Despite these benefits, the utilisation of insulin pump therapy in the UK has remained low compared with other countries - for instance, only $6 \%$ in the UK, lagging behind other European countries such as Germany, Norway (>15\%) and America (>40\%). ${ }^{3}$

\section{Role of ABCD IPN-UK}

Ongoing professional support and development is a prerequisite for the expansion of UK insulin pump services. In 2013 the National Pump Audit identified healthcare professional training as a key barrier to the growth of insulin pump therapy in the UK. ${ }^{4}$ Similarly, trainee doctors also reported little experience of training in insulin pumps. ${ }^{5}$ There is currently no dedicated forum to support the 160 UK insulin pump teams who are delivering

Derby Teaching Hospitals NHS Foundation Trust, Derby, UK

2 Harrogate and District NHS Foundation Trust, Harrogate, UK

University Hospitals of Leicester, Leicester, UK

Address for correspondence: Dr Emma G Wilmot Consultant Diabetologist, Derby Teaching Hospitals NHS Foundation Trust, Derby, UK.

Tel: +44 (0)1332 787696

E-mail: emma.g.wilmot@gmail.com

Br J Diabetes 2016;16:33-34

http://dx.doi.org/10.15277/bjd.2016.061
Box 1 Role of the IPN-UK

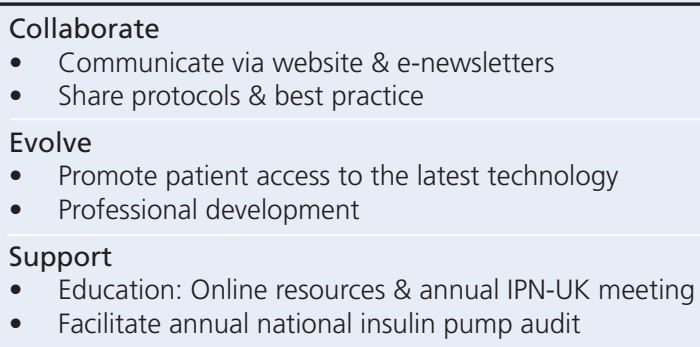

insulin pump therapy and the associated emerging technologies. The authors hope that the IPN-UK will fill this gap, providing a platform for teams to communicate and work towards a shared vision of best practice.

\section{Working together to enhance patient access to technology}

The IPN-UK aims to support insulin pump teams by providing opportunities for collaboration and education (Box 1). There are many clinical areas relevant to pump therapy with no clear guidance or consensus. How do you continue to expand your service to meet the needs of your patients within the financial constraints of the NHS? How do you interpret downloads in clinic with the limited time available? What are the optimal settings for predictive low glucose suspend? How do you manage the patient on a pump who is not monitoring their glucose regularly? What do you do when a patient on CSII is lost to follow-up? These are just some of the examples of the challenges presented to insulin pump teams in their day-to-day practice and the authors thought it would be useful for teams to have the opportunity to come together to share ideas, leading to the development of protocols and best practice documents hosted on the ABCD IPN-UK website.

\section{NHS diabetes insulin pump network: issues previously} identified

The previous, very successful, NHS diabetes insulin pump network identified a number of themes which are briefly discussed below. The ABCD IPN-UK hopes to build on these issues.

Service development

- Capacity planning for insulin pump services was very topical; what staffing were required to initiate and support insulin pump therapy? The national service level audit provided benchmarking information. Larger centres reported their experience with using virtual consultations to increase capacity for follow-up of pump users.

- Reference centres for pump therapy: would there be benefit in having a few centres in each region to support smaller or recently created pump services? Whilst all regions agreed that it would 
be very valuable to have such centres of expertise to mentor other centres, there was a recognition that this could not happen if it represented a significant increase in unfunded work for the reference centre.

- Transition pump service: what would these look like? There was concern about how best to organise transition services in general, and specifically for pump users. There was particular tension in areas where there is a mismatch between a big paediatric pump service and a much smaller adult service.

\section{Professional development}

- Developing staff to deliver insulin pump therapy services: how to access training for staff? It was recognised that there were a limited number of pump training courses for healthcare professionals and that there was a need to try and expand the opportunities, possibly through an e-learning packages. In addition, there was a need to provide information about pump therapy for healthcare professionals from settings where they might encounter pump users, such as the emergency department, labour ward and operating theatres.

\section{Funding}

- Funding the insulin pump service: how to ensure adequate income was obtained to support the necessary staffing? There was a lot of discussion about developing a tariff for pump therapy and at the South Region meeting Nick Vaughan from Brighton, who had been leading on the development of tariffs for diabetes at the DH, outlined the work he had done to obtain an OPCS4 code for insulin pump therapy which would allow creation of a tariff.

- Use of continuous glucose monitoring (CGM): how could CGM be integrated into a pump service?

\section{Clinical pathways}

- Standardising pathways to pump therapy: what should the pump pathway look like for a new pump user prior to initiation of pump therapy and for the first year thereafter; and for ongoing support for pump users after the first year and when the time comes to change their pump? There was a lot of support for group education and updates for existing pump users to prevent user fatigue and maintain improvements in glycaemic control, and improve the efficiency of service delivery.

- Out-of-hours support for insulin pump users: should there be 24/7 clinical support for insulin pump users? Most adult services were unable to provide this support, but there was a consensus that this would be ideal, with the pump companies providing technical support.

- Developing outcome measures for the success of insulin pump therapy beyond $\mathrm{HbA}_{1} c$ : what other benefits may pump users obtain from this therapy which can be effectively measured? There was significant demand for standardised measures of hypoglycaemia episodes and awareness, and a quality of life questionnaire relevant to pump therapy.

\section{Controversies in pump therapy}

- Managing non-attenders at pump clinic was a topic which generated a lot of heated commentary

- Re-use of insulin pumps and trials of insulin pump therapy drew an unprecedented sharing of practice, uncovering significant
Box 2 IPN-UK meeting programme 21st April 2016, Manchester

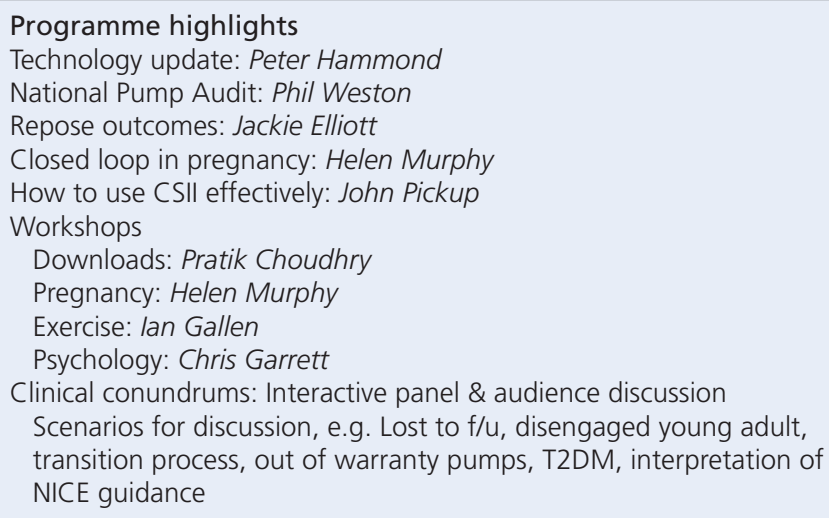

Box 3 How to register

Inaugural IPN-UK meeting

21st April 2016, Manchester

Register at www.IPN-UK.co.uk

divergence in approach and prompting calls for definitive guidance at the regional network meetings.

\section{$A B C D$ IPN-UK inaugural meeting}

The IPN-UK inaugural meeting will discuss some of the issues identified above. The meeting is on the 21st of April 2016 in Manchester, the day before the $A B C D$ Annual Spring Meeting. Highlights from the IPN-UK meeting programme can be seen in Box 2. Delegates will have access to iPad technology at the meeting, which will allow for interactive case discussion. You can register as a member of the IPNUK and book your place at the meeting at www.ipn-uk.co.uk (Box 3). UK-IPN membership is open to all UK adult and paediatric multidisciplinary clinicians who work with services which deliver - or wish to deliver - CSII therapy. We look forward to seeing you there.

Conflict of interest EW has received speaker honoraria, research \& educational grants from: Abbott, Diasend, Eli Lilly, GSK, Novo Nordisk, Roche, Sanofi Aventis. PH has received honoraria for lecturing and advisory board work from Medtronic, Roche, Abbott, Johnson and Johnson, Novo Nordisk and Lilly. Funding The $A B C D$ IPN-UK has received pledges of financial support from Gold Sponsors: CellNovo, Diasend, Roche and Silver Sponsors: Abbott and Medtronic.

\section{References}

1. Lauritzen T, Pramming S, Deckert T, Binder C. Pharmacokinetics of continuous subcutaneous insulin infusion. Diabetologia 1983;24:326-9. http://dx.doi.org/10.1007/BF00251817

2. Pickup JC. Insulin-pump therapy for type 1 diabetes mellitus. $N$ Engl $J$ Med 2012;366:1616-24. http://dx.doi.org/10.1056/NEJMct1113948

3. Pickup J. Insulin pumps. Int J Clin Pract Suppl 2011;170:16.

4. Association of British Clinical Diabetologists, Diabetes UK, JDRF (2013) The United Kingdom insulin pump audit. ABCD, Diabetes UK, JDRF. Available at: https://www.diabetes.org.uk/Documents/News/The United_Kingdom_Insulin_Pump_Audit_May_2013.pdf

5. Grant $P$, Cheer $K$, Herring $R$, et al. CSII experience among higher specialist trainees: a Young Diabetologists and Endocrinologists Forum survey. Practical Diabetes 2013;30:332-5. http://dx.doi.org/10.1002/pdi.1806 